Site populations and short range order in aluminosilicates investigated by $27 \mathrm{Al}$ solidstate NMR

Larsen, Flemming Hofmann; Farnan, lan

Published in:

Journal of Physical Chemistry Part B: Condensed Matter, Materials, Surfaces, Interfaces \& Biophysical

DOI:

10.1021/jp049603d

Publication date:

2004

Document version

Early version, also known as pre-print

Citation for published version (APA):

Larsen, F. H., \& Farnan, I. (2004). Site populations and short range order in aluminosilicates investigated by

$27 \mathrm{Al}$ solid-state NMR. Journal of Physical Chemistry Part B: Condensed Matter, Materials, Surfaces, Interfaces \& Biophysical, 108(28), 9764-9771. https://doi.org/10.1021/jp049603d 


\title{
Site Populations and Short Range Order in Aluminosilicates Investigated by ${ }^{27} \mathrm{Al}$ Solid-State NMR
}

\author{
Flemming H. Larsen ${ }^{\S}$ and Ian Farnan* \\ Department of Earth Sciences, University of Cambridge, Downing Street, \\ Cambridge CB2 3EQ, United Kingdom
}

Received: January 29, 2004; In Final Form: April 30, 2004

\begin{abstract}
Site populations in $\mathrm{Al}_{2} \mathrm{Si}_{2} \mathrm{O}_{5}$ kyanite and short range order parameters in $\mathrm{CaAl}_{2} \mathrm{Si}_{2} \mathrm{O}_{8}$ anorthite have been determined by using ${ }^{27} \mathrm{Al}$ multiple quantum magic angle spinning NMR with quadrupolar Carr-PurcellMeiboom-Gill echo train and FAM-II triple quantum to single quantum conversion pulses (MQ-QCPMGMAS NMR). Significant increases in resolution in the isotropic dimension were obtained by using the increased signal intensities to extend $t_{1}$ acquisition times. Detailed calculations were used to optimize pulse sequences and then evaluate the accuracy of signal intensity to site abundances based on $C_{\mathrm{Q}}$ and resonance offset variation in the mineral kyanite. The same approach was used to investigate a well-ordered anorthite and a range of disordered anorthite samples annealed at $1400{ }^{\circ} \mathrm{C}$ between $1 \mathrm{~min}$ and $179 \mathrm{~h}$. Because of intrinsic disorder accurate site populations were impossible to obtain for these samples but instead upper bounds for the order parameter were determined. Furthermore, the spectra of the annealed samples indicated that there was a distribution of EFG parameters for several sites (e.g. $m 000$ and $m z 00$ ), which suggests that these sites are important in the ordering process.
\end{abstract}

\section{Introduction}

Aluminosilicates are an important class of materials both in the Earth Sciences and Materials Science. In the early 1980s it became possible to quantitatively determine $\mathrm{Al} / \mathrm{Si}$ local ordering schemes in aluminosilicates by using high-resolution ${ }^{29} \mathrm{Si}$ MAS NMR. The Si chemical shift was sensitive to the number of Al second neighbors in framework materials which allowed the number of energetically unfavored $\mathrm{Al}-\mathrm{O}-\mathrm{Al}$ linkages to be determined in materials prepared under different conditions. ${ }^{1-6}$ This provided insight into the thermodynamic parameters controlling the structure of these materials, and in particular, the competition between long-range elastic ordering processes and local interactions. However, the local $\mathrm{Al} / \mathrm{Si}$ ordering information was only uniquely defined for schemes of complete order or a random distribution (unusual); ${ }^{72} \mathrm{Si}$ NMR spectra of intermediate ordering schemes are not unique to a particular $\mathrm{Al} / \mathrm{Si}$ distribution.

The advent of high-resolution NMR techniques for quadrupolar nuclei such as dynamic-angle spinning (DAS), ${ }^{8-10}$ doublerotation (DOR), ${ }^{9,11,12}$ satellite transition MAS (STMAS), ${ }^{13,14}$ and multiple-quantum MAS (MQ-MAS) ${ }^{15-18}$ provided a means to constrain the $\mathrm{Al} / \mathrm{Si}$ distribution in the intermediate case much more precisely by performing $2 \mathrm{D}$ or special $1 \mathrm{D}{ }^{27} \mathrm{Al} \mathrm{NMR}$ experiments. Among these the MQ-MAS experiment is the least technological demanding experiment as it can be performed in a standard MAS probe and it is not extremely sensitive to adjustment of the magic angle. One drawback of this method has been the lack of quantitative information when a broad range of quadrupolar coupling constants $\left(C_{\mathrm{Q}}\right)$ are present in the sample, because the intensities of the resonances in the isotropic projection are nonlinearly scaled by the magnitude of $C_{\mathrm{Q}} \cdot{ }^{19,20}$

* Address correspondence to this author. Fax: +44 1223333450 . Phone: +44 1223333 431. E-mail: ifarnan@esc.cam.ac.uk.

$\S$ Present address: Department of Protein Chemistry, Institute of Molecular Biology, University of Copenhagen, Øster Farimagsgade 2A, DK1353 København K, Denmark.
Several approaches have been used to increase the sensitivity of the experiment ${ }^{21-28}$ but none of these approaches produced an isotropic projection in which the intensities of the various sites are independent of their $C_{\mathrm{Q}}$. To a lesser extent differences in $\eta_{\mathrm{Q}}$ and $\delta_{\text {iso }}$ also affect the intensity. The present work is aimed at determining any systematics in $\mathrm{Al}$ shifts with neighbor distributions and extracting relative site populations by iterative fitting of the isotropic projection based upon the anisotropic parameters determined by fitting of the anisotropic traces.

To obtain optimum sensitivity we employed the ${ }^{27} \mathrm{Al}$ MQ-QCPMG-MAS pulse sequence ${ }^{20,29,30}$ using a train of rotor synchronized $\pi$-pulses for mixing and numerically optimized FAM-II type conversion pulses ${ }^{27}$ which combines the sensitivity enhancements in the isotropic as well as in the anisotropic dimension. The method is tested on the aluminosilicate mineral kyanite $\left(\mathrm{Al}_{2} \mathrm{SiO}_{5}\right)$ where site populations are known and then used to determine populations and local details of $\mathrm{Al} / \mathrm{Si}$ ordering from $\mathrm{Al}$ spectra in a suite of crystalline anorthites $\left(\mathrm{CaAl}_{2} \mathrm{Si}_{2} \mathrm{O}_{8}\right)$ with various degrees of order.

\section{Experimental and Methods}

The experiments were performed on a Chemagnetics Infinity 400 spectrometer, using a double resonance Chemagnetics T3 probe equipped with $4 \mathrm{~mm}$ zirconia rotors. For ${ }^{27} \mathrm{Al}$ the Larmor frequency was $104.24 \mathrm{MHz}$ and the rf field strength for the hard pulses was $151 \mathrm{kHz}$ whereas the rf field strength for the soft pulses was 24.4 and $14.7 \mathrm{kHz}$ for kyanite and the anorthites, respectively. All experiments employ the MQ-QCPMG-MAS pulse sequence ${ }^{20,29,30}$ displayed in Figure 1, using a 24-step phase cycle and hypercomplex data acquisition which results in a phase-sensitive isotropic projection. For all experiments an interpulse spacing of $0.3 \mu$ s for the FAM-II pulses, $\tau_{3}=\tau_{4}=$ $35.00 \mu$ s and $\tau_{\mathrm{a}}=\tau_{\mathrm{d}}=2.0 \mathrm{~ms}$ were employed.

Compared to the previous versions of the MQ-QCPMG-MAS pulse sequence the present one employs a train of rotorsynchronized $\pi$-pulses for mixing instead of the $z$-filter. As the 
(a)
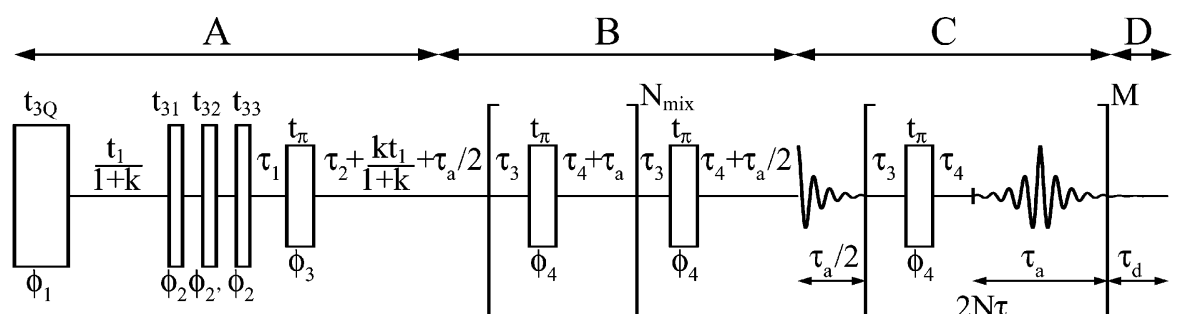

(b)

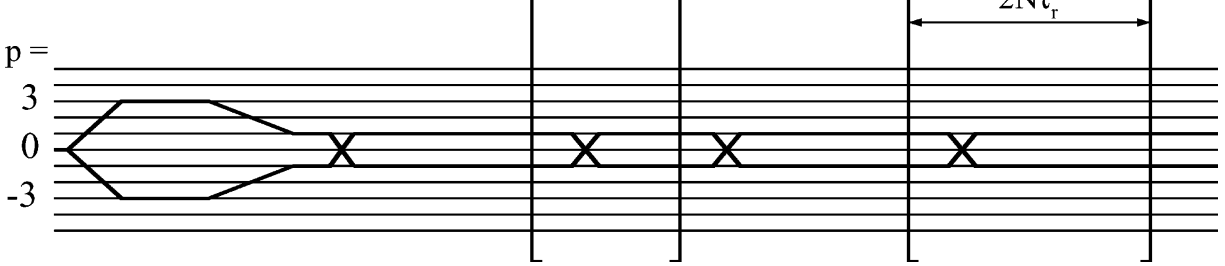

Figure 1. Pulse sequence (a) and corresponding coherence transfer pathway (b) for the split- $t_{1}$ MQ-QCPMG-MAS experiment, using FAM-II pulses for conversion of triple-to-single quantum conversion and $N_{\text {mix }}$ selective $\pi$-pulses for mixing. $t_{3 \mathrm{Q}}$ is the multiple quantum excitation pulse, $t_{3 j}, j=1,2,3$, are the FAM-II pulses, $t_{\pi}$ denotes the selective $\pi$-pulses, and $2 N \tau_{\mathrm{r}}=\tau_{3}+\tau_{4}+\tau_{\mathrm{a}}+t_{\pi}$. The phase cycle employs the following phases: $\phi_{j}=2 \pi / N_{j}$, in which $N_{j}=6,4$ for $j=1,3 . \phi_{2}=0, \phi_{2^{\prime}}=\pi$, and $\phi_{4}=0$. Hypercomplex data acquisition is obtained by increasing $\phi_{1}$ with $\pi / 6$.

mixing pulses are not phase cycled individually they balance the population of the $+1 Q$ and $-1 \mathrm{Q}$ levels of the central transition to produce a pure absorption phase 2D spectrum. Here 2 or 3 mixing pulses spaced equal to the spacing of the $\pi$-pulses during acquisition were sufficient to avoid phase distortions. All spectra are processed with the NMRPipe program. ${ }^{31}$

Due to the two parts of the $t_{1}$ evolution period two spinning sideband manifolds are associated with each resonance in the isotropic dimension. One manifold with sidebands separated by $\omega_{\mathrm{r}} /(2 \pi(1+k))$ from the evolution of multiple quantum $(m Q)$ coherence in the first part of the isotropic evolution period and $k \omega_{\mathrm{r}} /(2 \pi(1+k))$ from the $n$ quantum $(n Q)$ coherence evolution in the second part of the isotropic evolution period. By adjusting the spectral width in the isotropic dimension to one of the "pseudo-spin rates" in either of the $m Q$ or $n Q$ evolution periods only one set of spinning sidebands is observed and more importantly the spin rate is easier adjusted to avoid spinning sidebands in the region of the isotropic resonances.

The theoretical approach for the numerical calculations is based on a previous approach ${ }^{20}$ and is presented only briefly. The chemical shift in the isotropic dimension, $\delta^{\prime}$, is calculated as $^{32}$

$$
\delta^{\prime}=\left(\left(\delta_{\text {iso }}+\frac{\omega_{\mathrm{Q}}{ }^{2}}{10 \omega_{0}{ }^{2}}\left(3+\eta_{\mathrm{Q}}{ }^{2}\right)\left(\frac{3\left(k n^{3}+m^{3}\right)}{k n+m}-4 I(I+1)\right)\right)\right.
$$

where $k=-(m / n)\left(\left[36 I(I+1)-17 m^{2}-10\right] /[36 I(I+1)-\right.$ $\left.\left.17 n^{2}-10\right]\right), \omega_{\mathrm{Q}}=2 \pi C_{\mathrm{Q}} /(4 I(2 I-1))$, and $C_{\mathrm{Q}}=e^{2} q Q / h$. According to eq 1 distributions in isotropic chemical shifts (for sites having identical EFG tensors) and distributions in $\omega_{\mathrm{Q}}{ }^{2}(3$ $+\eta_{\mathrm{Q}^{2}}$ ) (for sites having identical isotropic chemical shifts) will be aligned along ridges in the $2 \mathrm{D}$ spectrum described as $\omega_{1}=$ $\alpha_{j} \omega_{2}, j \in\{$ iso, Q $\}$ in which $\alpha_{\text {iso }}=1$ is the slope for distribution of isotropic chemical shifts, $\alpha_{\mathrm{Q}}=\left[3\left(\mathrm{kn}^{3}+\mathrm{m}^{3}\right)-4(\mathrm{kn}+\mathrm{m})\right.$ $I(I+1)] /[(k n+m)(3-4 I(I+1))]$ is the slope for distribution of EFG-parameters, $\omega_{1}$ is the angular frequency in the isotropic dimension, and $\omega_{2}$ is the angular frequency in the anisotropic dimension. Specifically for spin $-5 / 2$ nuclei with the coherence transfer pathway ${ }^{33}(0 \rightarrow(3 Q) \rightarrow(1 Q) \rightarrow(-1 Q) \rightarrow( \pm 1 Q)$ etc. $)$, $k=19 / 12, m=3$, and $n=-1$ the slope for $\alpha_{\mathrm{Q}}$ is $-10 / 17$ for the distributions of EFG parameters.

Before discussing the actual experiments optimization of the multiple quantum pulses will be addressed. When a wide range of $C_{\mathrm{Q}}$ values are present in the sample it becomes difficult or nearly impossible to optimize the pulse lengths experimentally for all sites because the sites with the more favorable anisotropic parameters will dominate the spectra. One way to avoid this problem is to optimize the pulses numerically to improve the conditions for the most difficult sites. Usually the most difficult properties relate to the site with the largest $C_{\mathrm{Q}}$, which can be estimated from the width of the central transition in a singlepulse MAS spectrum. Alternatively, the most difficult site could be the least populated one.

Here the ${ }^{27} \mathrm{Al}$ rf pulses were optimized for $C_{\mathrm{Q}}$ values of 10 and $8.5 \mathrm{MHz}$ for kyanite and anorthite, respectively, using an rf field strength $\left(-\omega_{\mathrm{rf}} / 2 \pi\right)$ of $150 \mathrm{kHz}$ and a spin rate $\left(\omega_{\mathrm{r}} / 2 \pi\right)$ of $15 \mathrm{kHz}$. All optimizations employed $\eta_{\mathrm{Q}}=0.0$ to reduce the computation time. The 3Q excitation pulses have been optimized for the symmetric $3 \mathrm{Q}$ transition, that is, the $(2,5)$-entry in the density matrix for a spin $-5 / 2$ nucleus. Subsequent transfer into the (1Q) coherence of the central transition, the $(3,4)$-entry in the density matrix, by FAM-II pulses is then performed under the restrictions of the phase cycle. The FAM-II pulses are separated by $0.3 \mu$ s to allow for phase switching. Optimum 3Q to $1 \mathrm{Q}$ transfer was obtained with two FAM-II pulses and addition of more pulses did not improve the numerical results. A factor of 2 increase in sensitivity was obtained compared with the transfer of $3 \mathrm{Q}$ to $1 \mathrm{Q}$ by a single pulse.

To explore the intensity dependence of the resonances in the isotropic projection as a function of $C_{\mathrm{Q}}$ and offset, isotropic projections were calculated for various magnitudes of $C_{\mathrm{Q}}$ and offsets as displayed in Figure 2. When the $C_{\mathrm{Q}}$ was varied the offset was kept constant at $0.0 \mathrm{kHz}$ whereas $C_{\mathrm{Q}}$ was fixed at 6.0 $\mathrm{MHz}$ when the offset was varied. In accordance with previous calculations ${ }^{16,34}$ the intensity of the isotropic peak is highly dependent on the magnitude of $C_{\mathrm{Q}}$ but furthermore the effect of the offset shows that $85 \%$ of the maximum intensity (see dotted line) is retained for offsets in the range between -5 and $+4 \mathrm{kHz}$ from the isotropic chemical shift whereas $95 \%$ is retained for offsets between -4 and $-2 \mathrm{kHz}$. The isotropic chemical shift and the second-order shift add up to $-2.245 \mathrm{kHz}$, which indicates that this sum would be the optimum choice of offset. It should be stressed that the effective excitation range depends on the rf field strength available.

By using the optimized pulse widths the experimental data were acquired and then processed according to the following procedure to determine the relevant isotropic and anisotropic 


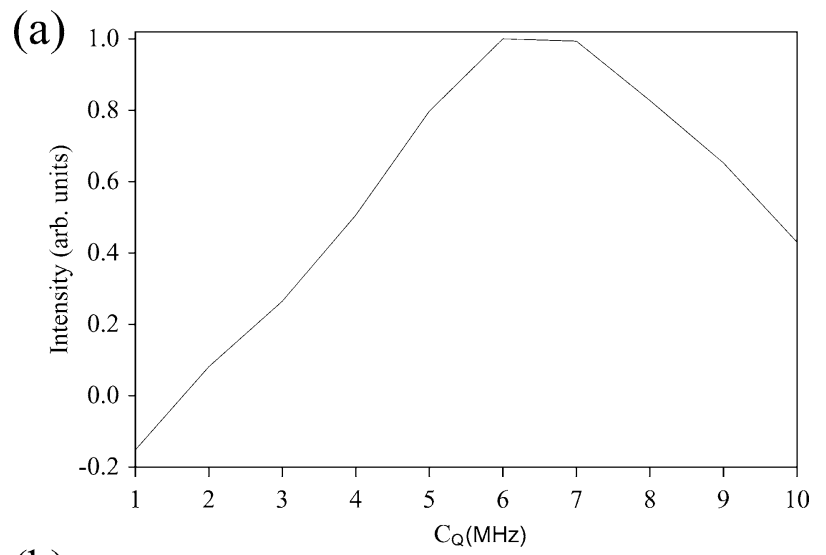

(b)

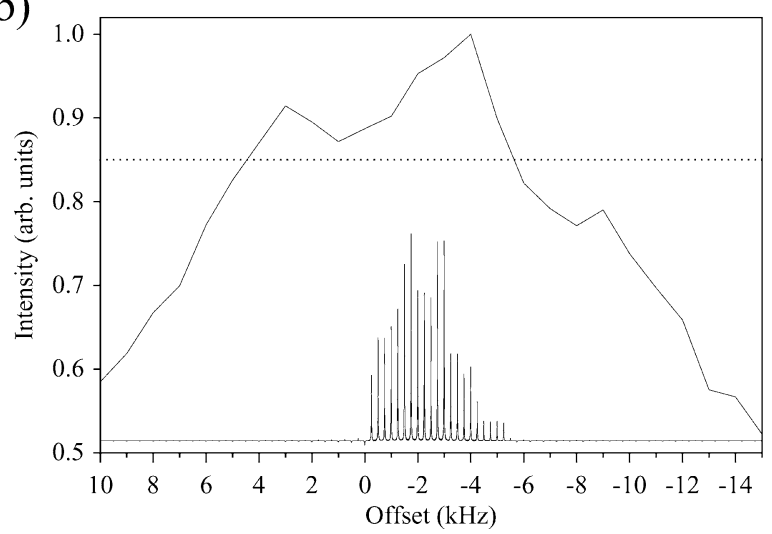

Figure 2. Calculated intensities of isotropic projections of ${ }^{27} \mathrm{Al}(104.24$ MHz) MQ-QCPMG-MAS spectra using rf-field strengths of 150 and $13.9 \mathrm{kHz}$ for hard and soft pulses, respectively. The pulse widths were $t_{3 \mathrm{q}}=3.0 \mu \mathrm{s}, t_{31}=0.6 \mu \mathrm{s}, t_{32}=0.4 \mu \mathrm{s}$, and $t_{33}=0.2 \mu \mathrm{s}$. Delays were $\tau_{1}=\tau_{2}=66.67 \mu \mathrm{s}$, using a spin rate, $\omega_{\mathrm{r}} / 2 \pi$, of $15000 \mathrm{~Hz}$, selective $\pi$-pulses of $12.0 \mu \mathrm{s}, N_{\text {mix }}=2$, and a dwell time of $10.0 \mu \mathrm{s}$. $192 t_{1}$ steps using $t_{1}$ increments of $172.222 \mu$ s were calculated. All calculations employ $\eta_{\mathrm{Q}}=0.5$. In part a, the offset is kept constant at $0.0 \mathrm{kHz}$ and $C_{\mathrm{Q}}$ is varied from 1 to $10 \mathrm{MHz}$ in steps of $1 \mathrm{MHz}$. In part b, $C_{\mathrm{Q}}$ is kept constant at $6.0 \mathrm{MHz}$ and the offset is varied from 10 to $-15 \mathrm{kHz}$ in steps of $1 \mathrm{kHz}$. A dotted line at a relative intensity of 0.85 is included as well as the QCPMG-MAS spectrum calculated by using ideal rfpulses, $C_{\mathrm{Q}}=6.0 \mathrm{MHz}, \eta_{\mathrm{Q}}=0.5$ and offset at $0.0 \mathrm{kHz}$.

parameters. First of all, the smallest possible additional line broadening is added to ensure optimum spectral resolution and the anisotropic traces corresponding to the resonances in the isotropic projection with the maximum intensity were extracted. Then $C_{\mathrm{Q}}$ and $\eta_{\mathrm{Q}}$ are determined for the various sites by iterative fitting of these traces under the restriction that the corresponding $\delta_{\text {iso }}$ has to fulfill eq 1 . These parameters were then used to fit the isotropic projection to quantify the site populations. For the calculated spectra the applied line broadenings for the individual sites are determined by deconvolution of the experimental projection into Lorentzian line shapes to compensate for differences in relaxation.

Iterative fitting and calculation of anisotropic traces and the isotropic projections were performed on a $2 \mathrm{GHz}$ PC Pentium IV, using a version of the software previously described ${ }^{20}$ modified to spin- $5 / 2$ nuclei. 144 and $987\left(\alpha_{\mathrm{CR}}, \beta_{\mathrm{CR}}\right)$ angles were selected according to the Zaremba tiling scheme ${ }^{35}$ for the calculation of isotropic projections and anisotropic traces, respectively, while the $\gamma_{\mathrm{CR}}$ angles were incremented equidistantly in 20 steps. All calculations employ real-time square pulses.

The kyanite and the ordered anorthite samples were natural samples whereas the disordered anorthite samples were those studied previously by ${ }^{29} \mathrm{Si}$ MAS $\mathrm{NMR}^{5}$ and were prepared according to the procedure described by Carpenter. ${ }^{36}$

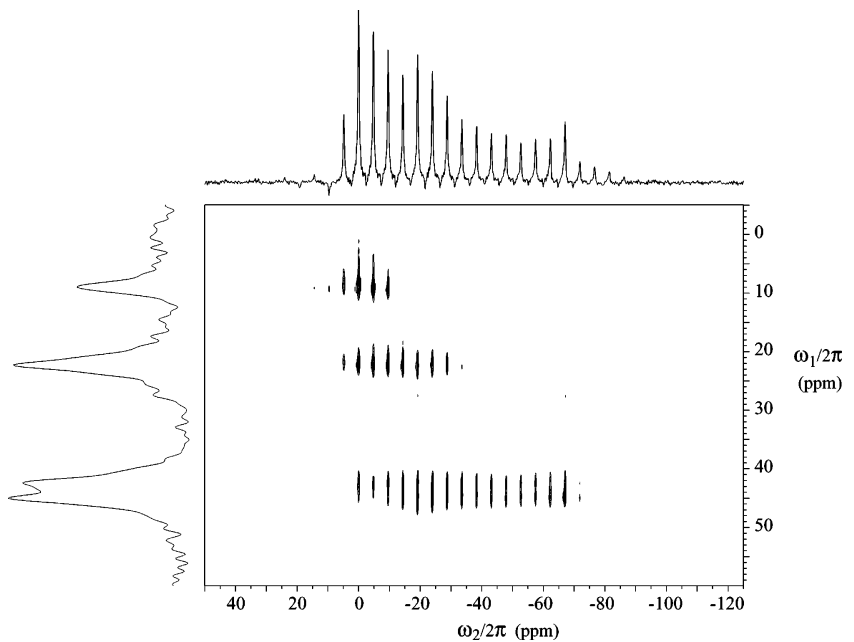

Figure 3. Experimental ${ }^{27} \mathrm{Al}(104.24 \mathrm{MHz})$ MQ-QCPMG-MAS spectrum of kyanite. The pulse widths were $t_{3 \mathrm{q}}=3.0 \mu \mathrm{s}, t_{31}=0.6 \mu \mathrm{s}$, $t_{32}=0.4 \mu \mathrm{s}$, and $t_{33}=0.2 \mu \mathrm{s}$. The delays were $\tau_{1}=\tau_{2}=64.90 \mu \mathrm{s}$, using a spin rate, $\omega_{\mathrm{r}} / 2 \pi$, of $15408 \mathrm{~Hz}$, selective $\pi$-pulses of $6.833 \mu \mathrm{s}$, $N_{\text {mix }}=2, M=10$, and a dwell time of $5.0 \mu \mathrm{s}$. 720 scans with a recycle delay of $2.0 \mathrm{~s}$ have been acquired for each of the $80 t_{1}$ steps, using $t_{1}$ increments of $166.661 \mu \mathrm{s}$. A Gaussian line broadening of $5 \mathrm{~Hz}$ has been applied in both dimensions.

\section{Results and Discussion}

Kyanite. Kyanite is an example of a compound with several octahedral sites that are very difficult to separate by standard

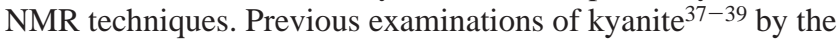
3Q-MAS method have not reported four distinct isotropic resonances because of overlapping resonances from the two sites with large quadrupole coupling constants and only recently all four sites have been resolved by using the Self-Compensation for Magic-Angle Misset (SCAM)-STMAS technique. ${ }^{40}$

The ${ }^{27} \mathrm{Al}$ MQ-QCPMG-MAS spectrum of kyanite is displayed in Figure 3. Four sites originating from octahedral aluminums are observed with isotropic intensities scaled according to their MQ excitation/conversion properties. The resonances from the two sites having $\delta_{\text {exp }}^{\prime}$ of 9.0 and $22.3 \mathrm{ppm}$ are very well separated but the other two resonances at 42.4 and $45.1 \mathrm{ppm}$ are separable but display a significant overlap. Compared to previously published spectra this shows that optimum pulse lengths and sufficiently long $t_{1}$ evolution times are important factors when two such spectroscopically challenging sites are to be distinguished. Due to the sensitivity gain provided by FAM-II a good S/N ratio is obtained even though only $5 \mathrm{~Hz}$ of Gaussian line broadening has been added in both dimensions prior to Fourier transform.

By iterative fitting of the four traces the anisotropic parameters in Table 1 have been obtained and in Figure 4 the experimental (Figure $4 \mathrm{a}-\mathrm{d}$ ) and calculated (Figure $4 \mathrm{e}-\mathrm{h}$ ) anisotropic traces are displayed. The parameters obtained in the present analysis agree well with previous results from singlepulse MAS at high field. ${ }^{41}$ Even though effects of finite pulses are included some differences between the experimental and calculated spectra are observed. Part of the reason for the differences is the very short rf pulses which cause the rise time and other pulse artifacts to be a relatively large part of the pulse and thereby introduce effects that are not accounted for by the theoretical assumption of perfectly square pulses.

To assess the efficiency of the calculations to quantify the population of Al sites by MQ-QCPMG-MAS, the parameters derived from the anisotropic traces have been used to fit the isotropic projection displayed in Figure 5b. Figure 5c displays the result of the isotropic calculation with use of the parameters 
TABLE 1: Quadrupole Coupling $\left(C_{\mathrm{Q}}, \eta_{\mathrm{Q}}\right)$, Isotropic Chemical Shift $\left(\delta_{\text {Iso }}\right)$ Parameters, Calculated $\left(\delta^{\prime}\right.$ calc $)$ and Experimental $\left(\delta_{\text {exp }}^{\prime}\right)$ Shifts in the MQ-QCPMG-MAS Spectra's Isotropic Projection, and Relative Population for the ${ }^{27} \mathrm{Al}$ Sites in Kyanite ${ }^{a}$

\begin{tabular}{|c|c|c|c|c|c|c|c|}
\hline site & $\operatorname{assign}^{b}$ & $C_{\mathrm{Q}}(\mathrm{MHz})$ & $\eta_{\mathrm{Q}}$ & $\delta_{\text {iso }}(\mathrm{ppm})$ & $\delta_{\text {calc }}^{\prime}(\mathrm{ppm})$ & $\delta_{\exp }^{\prime}(\mathrm{ppm})$ & pop. $(\%)$ \\
\hline $1^{c}$ & A2 & $3.73 \pm 0.10$ & $0.55 \pm 0.20$ & $4.0 \pm 0.5$ & 9.0 & 9.0 & 26.6 \\
\hline $1^{b}$ & A2 & $3.6 \pm 0.1$ & $0.85 \pm 0.10$ & $4.0 \pm 0.3$ & 9.2 & & 27 \\
\hline $2^{c}$ & A3 & $6.53 \pm 0.10$ & $0.36 \pm 0.20$ & $7.8 \pm 0.5$ & 22.2 & 22.3 & 21.2 \\
\hline $2^{b}$ & A3 & $6.6 \pm 0.1$ & $0.59 \pm 0.05$ & $7.7 \pm 0.3$ & 23.5 & & 26 \\
\hline $3^{c}$ & A4 & $9.52 \pm 0.10$ & $0.36 \pm 0.20$ & $11.7 \pm 0.5$ & 42.4 & 42.4 & 25.5 \\
\hline $3^{b}$ & A4 & $9.2 \pm 0.1$ & $0.38 \pm 0.10$ & $11.0 \pm 0.5$ & 39.8 & & 24 \\
\hline $4^{c}$ & A1 & $9.94 \pm 0.10$ & $0.54 \pm 0.20$ & $9.9 \pm 0.5$ & 45.1 & 45.1 & 26.6 \\
\hline $4^{b}$ & A1 & $10.1 \pm 0.1$ & $0.27 \pm 0.10$ & $14.9 \pm 0.5$ & 48.8 & & 23 \\
\hline
\end{tabular}

${ }^{a}$ Accuracies are estimated by numerical calculations and visual inspection. The ${ }^{27} \mathrm{Al}$ chemical shifts are on the $\delta$ scale and referenced $1.0 \mathrm{M}$ $\mathrm{Al}\left(\mathrm{NO}_{3}\right)_{3}$ (aq). ${ }^{b}$ Reference 41 (single-pulse MAS NMR). ${ }^{c}$ This work.

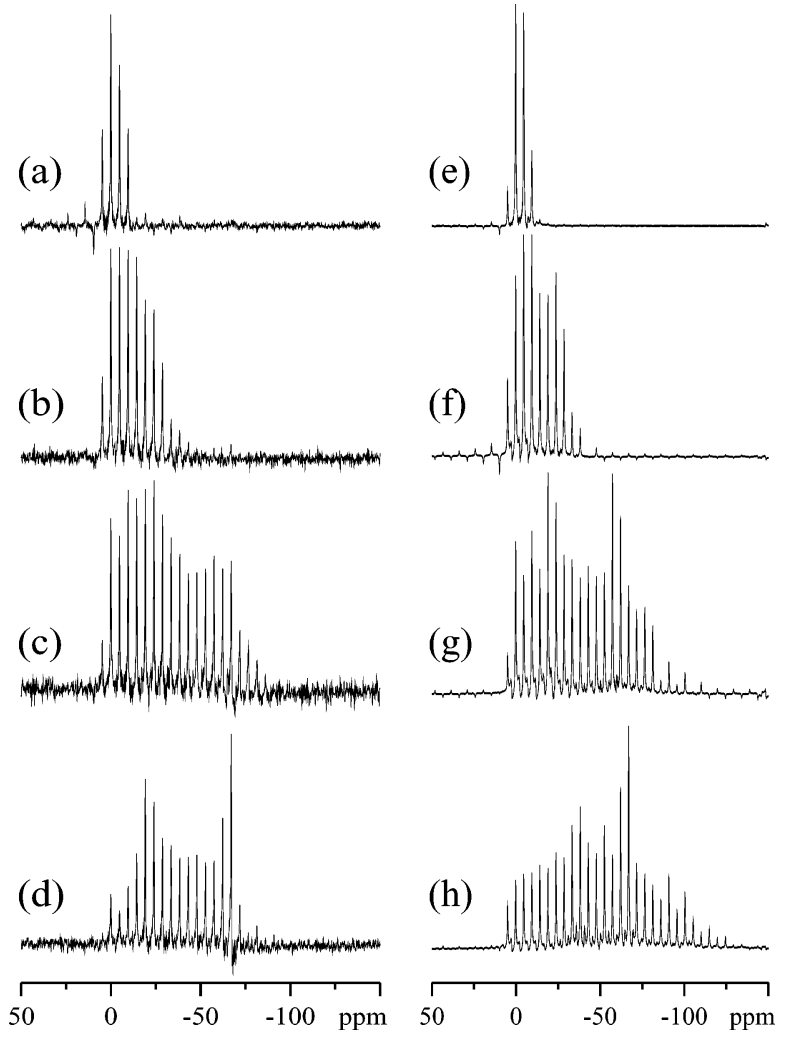

Figure 4. ${ }^{27} \mathrm{Al}(104.24 \mathrm{MHz})$ experimental $(\mathrm{a}-\mathrm{d})$ and calculated $(\mathrm{e}-\mathrm{h})$ (using parameters in Table 1) anisotropic traces for kyanite. The traces correspond to $\delta_{\text {exp }}^{\prime}=$ (a) 9.0, (b) 22.3, (c) 42.4, and (d) 45.1 ppm, respectively. The calculated spectra were apodized by a Lorentzian line broadening of $50 \mathrm{~Hz}$.

listed in Table 1 assuming equal populations of the four sites whereas the spectrum in Figure 5a is the result of iterative fitting of the isotropic projection (Figure 5b) with use of populations (\%) of 26.6:21.2:25.5:26.6 for sites 1-4, respectively. From a previous extensive analysis by MAS NMR at $17.6 \mathrm{~T}^{41}$ it was necessary to use relative populations( $\%$ ) of 27:26:24:23. A priori the four sites should be equally populated. This gives us a standard deviation of $2.23 \%$ whereas this value is $1.58 \%$ for the populations obtained by high-field MAS. Apart from slightly more inaccurate site populations compared to the values obtained from high-field MAS this demonstrates that by using MQQCPMG-MAS experiments reasonable site populations can be obtained even at intermediate magnetic field strengths. To validate the parameters the MAS spectrum was calculated by using the anisotropic parameters and relative populations obtained from our MQ-QCPMG-MAS spectrum. The calculated and the experimental MAS spectra are displayed in Figure 6.

Anorthite. Anorthite belongs to the plagioclase feldspar class of minerals which are characterized by the composition $\mathrm{Na}_{1-x} \mathrm{Ca}_{x} \mathrm{Al}_{1+x} \mathrm{Si}_{3-x} \mathrm{O}_{8}$, where $0 \leq x \leq 1$. When $0.9 \leq x \leq 1.0$

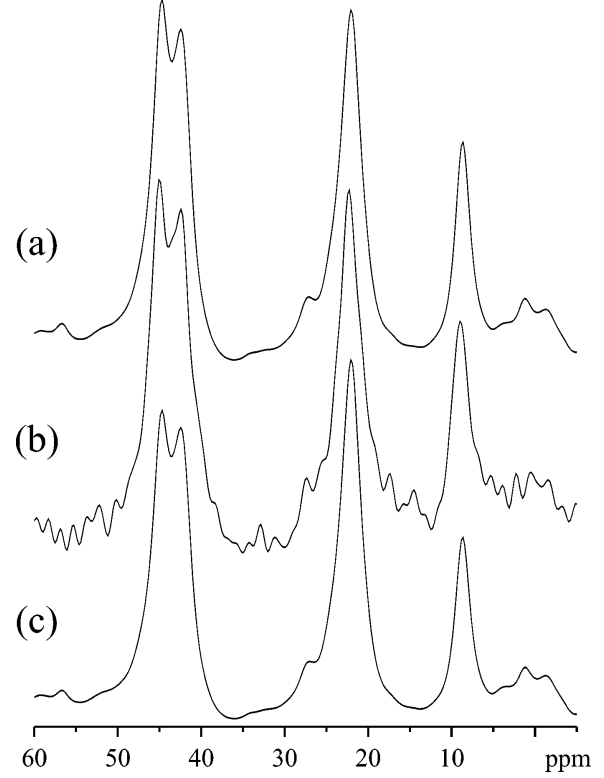

Figure 5. ${ }^{27} \mathrm{Al}(104.24 \mathrm{MHz})$ experimental (b) and calculated (a, c) (using parameters in Table 1) isotropic projections for kyanite. Spectra $\mathrm{a}$ and $\mathrm{b}$ are sums of individually calculated isotropic projections of the four sites, using Lorentzian line broadenings of 130 (site 1), 155 (site 2), 160 (site 3), and 130 (site 4) Hz. For the spectrum in part a, the sites are weighted by 0.266 (site 1), 0.212 (site 2), 0.255 (site 3), and 0.266 (site 4), respectively. In part c the calculated spectrum is an equally weighted sum of the individual isotropic spectra.

the feldspar is classified as anorthite and denoted $\mathrm{An}_{x * 100}$. In this work a well-characterized crystalline $\mathrm{An}_{100}$ as well as a series of disordered $\mathrm{An}_{100}$ samples are analyzed.

Anorthite represents a challenge in terms of resolution because it contains 8 tetrahedrally coordinated $\mathrm{Al}$ sites having a wide span of $C_{\mathrm{Q}}$ values ranging from 2.7 to $8.4 \mathrm{MHz}$ according to single-crystal NMR analysis. ${ }^{42}$ The crystalline sample of anorthite has previously been investigated by ${ }^{29} \mathrm{Si} \mathrm{MAS} \mathrm{NMR}^{5}$ in which 6 resonance lines due to partial overlap of signals from the $8 \mathrm{Si}$ sites were observed.

The ${ }^{27} \mathrm{Al}$ MQ-QCPMG-MAS spectrum of crystalline anorthite is displayed in Figure 7. The inset shows the ${ }^{29} \mathrm{Si}$ MAS NMR spectrum of the same sample. The resolution in the isotropic projection of the ${ }^{27} \mathrm{Al}$ MQ-QCPMG-MAS spectrum is clearly superior with a resonance for each of the 8 crystallographically distinct tetrahedral sites resolved. There are no obvious peaks due to $\mathrm{Al}$ resonances with $\mathrm{Al}$ second neighbors. There are shoulders at $\sim 83$ (to peak 6 ) and $\sim 71$ (to peak 3 ) ppm and a resolved peak at $\sim 63 \mathrm{ppm}$ that could conceivably be attributed to shifted resonances due to the remaining $\mathrm{Al}-\mathrm{O}-\mathrm{Al}$ linkages in this ordered sample. At the present time there is no way to attribute these additional peaks to those that would carry the local ordering information in an analogous way to the ${ }^{29} \mathrm{Si}$ chemical shifts that would be present when $\mathrm{Si}$ has $\mathrm{Al}$ second 


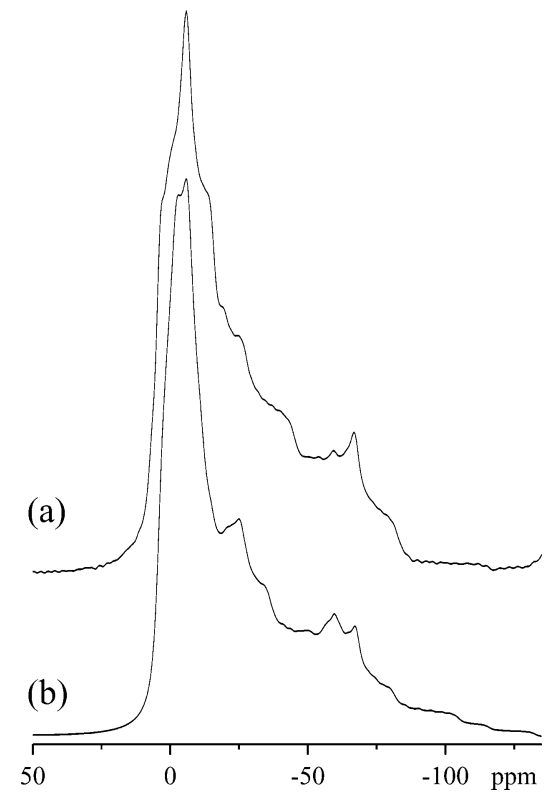

Figure 6. ${ }^{27} \mathrm{Al}(104.24 \mathrm{MHz}$ ) experimental (a) and calculated (b) (using parameters in Table 1) MAS spectra of kyanite. The experimental spectrum is a single pulse MAS spectrum acquired at a spin rate of $15000 \mathrm{~Hz}$, using a $0.5 \mu$ s excitation pulse (rf-field strength: $33 \mathrm{kHz}$ ), a recycle delay of $2 \mathrm{~s}$, and 1024 scans. The experimental spin rate and ideal rf pulses are employed for the calculated spectrum. Lorentzian line broadenings of 1 and $300 \mathrm{~Hz}$ have been applied to the experimental and calculated spectra, respectively.

neighbors rather than Si. The very high resolution of the anorthite spectrum together with a robust calculation of excitation and detection effects on signal intensity should form the basis for an analysis of site populations. These site populations will give the overall number of $\mathrm{Al}-\mathrm{O}-\mathrm{Al}$ linkages by the deviation of the populations from a uniform distribution. In
Figure 8 the anisotropic traces corresponding to the various isotropic resonances (Figure $8 \mathrm{a}-\mathrm{h}$ ) are displayed along with the calculated traces (Figure 8i-p), using the parameters in Table 2 obtained by iterative fitting. The experimental and calculated traces agree very well and only the parameters for site 1 are not well-constrained as they are determined from only 2 spin-echo sidebands (Figure 8a,i). Comparison with parameters obtained from single-crystal $\mathrm{NMR}^{42}$ (see Table 2) shows that the $C_{\mathrm{Q}}$ values are similar whereas differences of up to 0.24 are observed for $\eta_{\mathrm{Q}}$. The Al sites in the single-crystal NMR analysis $^{42,43}$ were assigned according to their crystallographic classification and based on the matching $C_{\mathrm{Q}}$ values it was possible to transfer the assignment to the present work.

The assignment of the $\mathrm{Al}$ sites in anorthite allows us to examine the variation of NMR chemical shifts with structural parameters in a similar way to Phillips et al. ${ }^{5}$ but with the advantage of a complete assignment. In Figure 9 the isotropic chemical shift is plotted as a function of the average $\mathrm{Al}-\mathrm{O}-\mathrm{Si}$ angle $^{44}$ along with the best linear fit. As expected from previous MAS analysis of aluminosilicates $\delta_{\text {iso }}$ decreases as a function of the mean $\mathrm{Al}-\mathrm{O}-\mathrm{Si}$ angle and the parameters for the linear fit are similar to those values previously determined for ordered structures. ${ }^{45}$ Furthermore our 8 data points represent an improvement on the previously determined values because they are taken from the same sample with the same order compared with previous data obtained from different samples that may vary in their ordering. No linear correlations between the EFG parameters and the structural parameters (bond lengths and bond angles) was found.

Having determined the anisotropic parameters for the 8 sites the corresponding isotropic projection may be calculated to quantify the relative populations. Figure 10 shows the calculated (Figure 10a,c) as well as the experimental (Figure 10b) isotropic projections. In Figure 10c the calculated spectrum with equally distributed sites is displayed whereas the spectrum in Figure

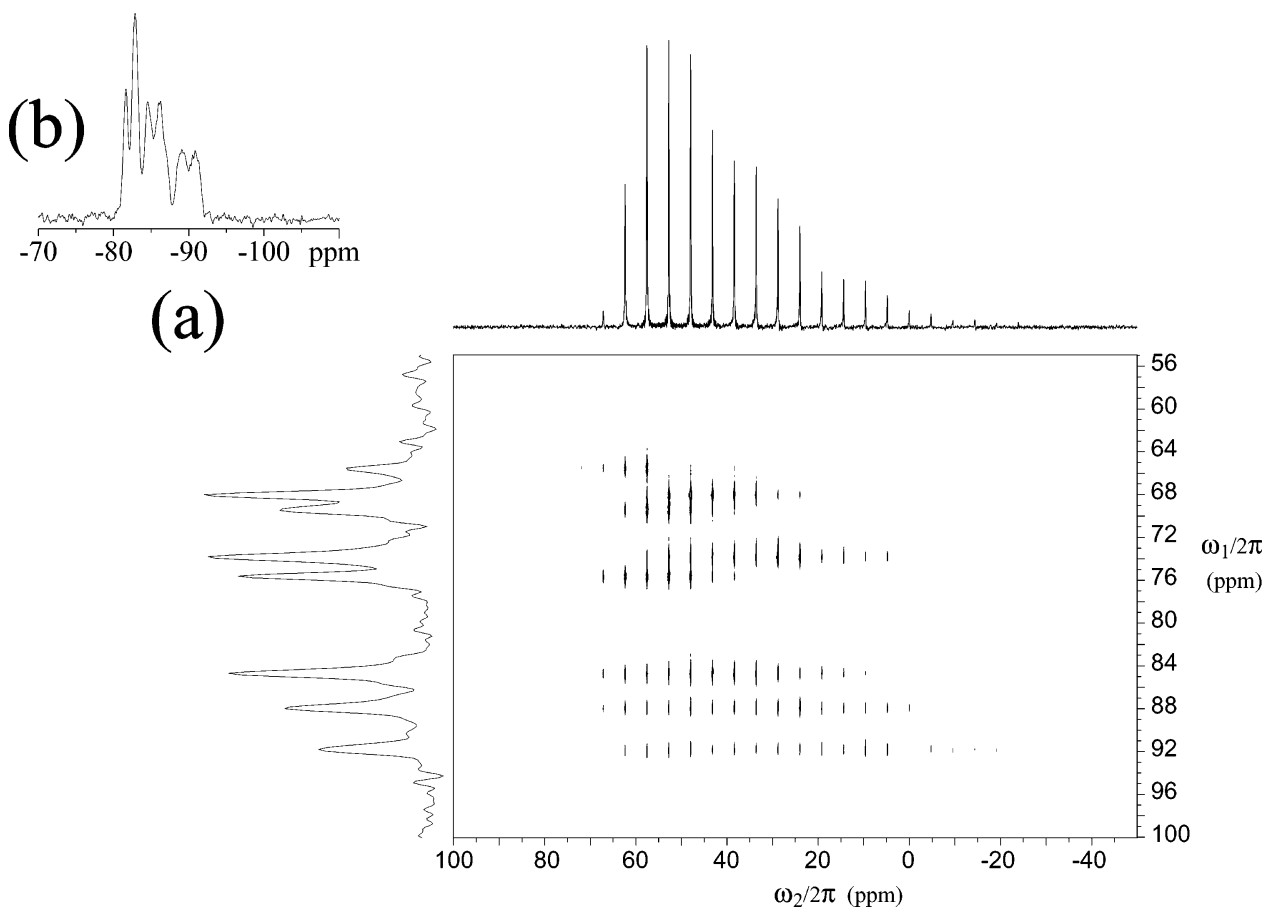

Figure 7. (a) Experimental ${ }^{27} \mathrm{Al}(104.24 \mathrm{MHz}) \mathrm{MQ}-\mathrm{QCPMG}-\mathrm{MAS}$ spectrum of anorthite. The pulse widths were $t_{3 \mathrm{q}}=3.4 \mu \mathrm{s}, t_{31}=0.7 \mu \mathrm{s}, t_{32}=$ $0.4 \mu \mathrm{s}$, and $t_{33}=0.2 \mu \mathrm{s}$, and the delays were $\tau_{1}=\tau_{2}=80.05 \mu \mathrm{s}$, using a spin rate $\left(\omega_{\mathrm{r}} / 2 \pi\right)$ of $12492 \mathrm{~Hz}$, selective $\pi$-pulses of $11.33 \mu \mathrm{s}, N_{\text {mix }}=$ $3, M=27$, and a dwell time of $10.0 \mu \mathrm{s}$. 48 scans with a recycle delay of $6.0 \mathrm{~s}$ have been acquired for each the $108 t_{1}$ steps, using $t_{1}$ increments of $206.799 \mu \mathrm{s}$. Gaussian line broadening of $5 \mathrm{~Hz}$ has been applied in both dimensions. The insert in part b is the experimental ${ }^{29} \mathrm{Si}$ single-pulse MAS spectrum of anorthite acquired with use of a $\pi / 16$ excitation pulse, a spin rate of $9000 \mathrm{~Hz}$, and 3081 scans with a recycle delay of 34 s. A Lorentzian line broadening of $10 \mathrm{~Hz}$ have been applied to this spectrum. 
TABLE 2: Quadrupole Coupling $\left(C_{\mathrm{Q}}, \eta_{\mathrm{Q}}\right)$, Isotropic Chemical Shift $\left(\delta_{\text {Iso }}\right)$ Parameters, Calculated $\left(\delta_{\text {calc }}^{\prime}\right)$ and Experimental $\left(\delta_{\text {exp }}^{\prime}\right)$ Shifts in the MQ-QCPMG-MAS Spectra's Isotropic Projection, Relative Population, and Mean Al-O-Si Angle $(\theta)^{44}$ for the ${ }^{27}$ Al Sites in Anorthite ${ }^{a}$

\begin{tabular}{|c|c|c|c|c|c|c|c|c|}
\hline site & $\operatorname{assign}^{b}$ & $C_{\mathrm{Q}}(\mathrm{MHz})$ & $\eta_{\mathrm{Q}}$ & $\delta_{\text {iso }}(\mathrm{ppm})$ & $\delta_{\text {calc }}^{\prime}(\mathrm{ppm})$ & $\delta_{\text {exp }}^{\prime}(\mathrm{ppm})$ & pop. (\%) & $\theta$ \\
\hline $1^{c}$ & $m z i 0$ & $2.53 \pm 0.10$ & $0.80 \pm 0.10$ & $63.0 \pm 0.5$ & 65.5 & 65.5 & 14.1 & 137.9 \\
\hline $1^{d}$ & $m z i 0$ & $2.66 \pm 0.12$ & $0.66 \pm 0.06$ & - & & & & \\
\hline $2^{c}$ & $m 0 i 0$ & $5.46 \pm 0.10$ & $0.39 \pm 0.05$ & $57.9 \pm 0.5$ & 68.1 & 68.0 & 12.9 & 145.4 \\
\hline $2^{d}$ & $m 0 i 0$ & $5.44 \pm 0.08$ & $0.42 \pm 0.02$ & - & & & & \\
\hline $3^{c}$ & 0000 & $4.27 \pm 0.10$ & $0.48 \pm 0.05$ & $63.1 \pm 0.5$ & 69.5 & 69.5 & 11.7 & 138.0 \\
\hline $3^{d}$ & 0000 & $4.32 \pm 0.07$ & $0.53 \pm 0.03$ & - & & & & \\
\hline $4^{c}$ & $m 000$ & $6.34 \pm 0.10$ & $0.84 \pm 0.05$ & $57.7 \pm 0.5$ & 73.8 & 73.8 & 15.6 & 144.3 \\
\hline $4^{d}$ & $m 000$ & $6.30 \pm 0.11$ & $0.88 \pm 0.02$ & - & & & & \\
\hline $5^{c}$ & $m z 00$ & $4.84 \pm 0.10$ & $0.75 \pm 0.05$ & $66.6 \pm 0.5$ & 75.6 & 75.6 & 10.0 & 133.5 \\
\hline $5^{d}$ & $m z 00$ & $4.90 \pm 0.05$ & $0.75 \pm 0.05$ & - & & & & \\
\hline $6^{c}$ & $00 i 0$ & $6.80 \pm 0.10$ & $0.55 \pm 0.10$ & $68.1 \pm 0.5$ & 84.6 & 84.7 & 13.3 & 131.1 \\
\hline $6^{d}$ & $00 i 0$ & $6.81 \pm 0.04$ & $0.65 \pm 0.02$ & - & & & & \\
\hline $7^{c}$ & $0 z 00$ & $7.56 \pm 0.10$ & $0.56 \pm 0.10$ & $67.5 \pm 0.5$ & 88.0 & 88.0 & 12.7 & 132.8 \\
\hline $7^{d}$ & $0 z 00$ & $7.25 \pm 0.21$ & $0.76 \pm 0.02$ & - & & & & \\
\hline $8^{c}$ & $0 z i 0$ & $8.50 \pm 0.10$ & $0.53 \pm 0.10$ & $66.2 \pm 0.5$ & 91.9 & 91.8 & 9.8 & 132.2 \\
\hline $8^{d}$ & $0 z i 0$ & $8.42 \pm 0.15$ & $0.66 \pm 0.01$ & & & & & \\
\hline
\end{tabular}

${ }^{a}$ Accuracies are estimated by numerical calculations and visual inspection. The ${ }^{27} \mathrm{Al}$ chemical shifts are on the $\delta$ scale and referenced $1.0 \mathrm{M}$ $\mathrm{Al}\left(\mathrm{NO}_{3}\right)_{3}$ (aq). ${ }^{b}$ Assignments according to refs 42 and $43 .{ }^{c}$ This work. ${ }^{d}$ Reference 42 (single-crystal NMR).

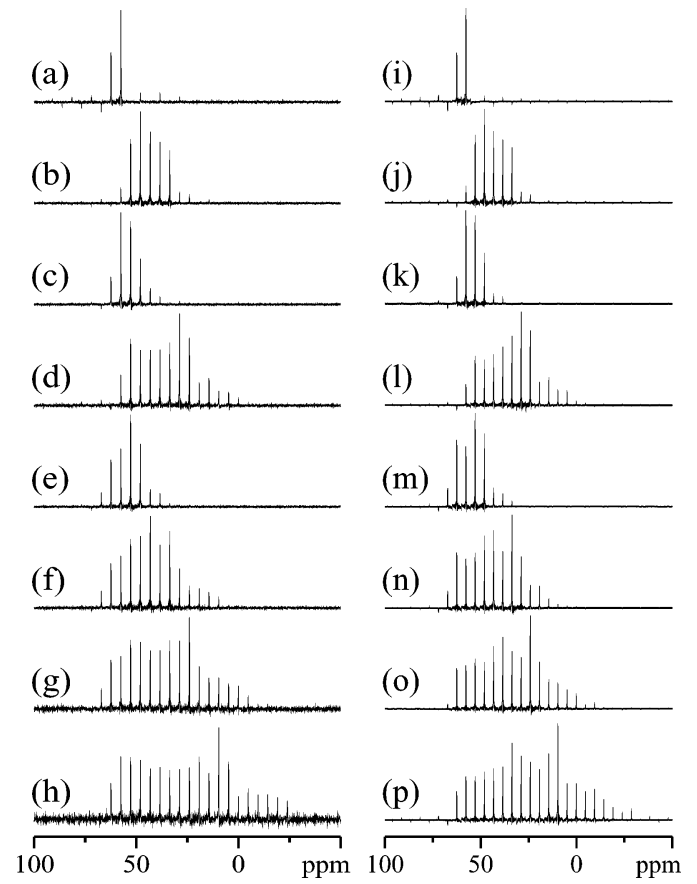

Figure 8. ${ }^{27} \mathrm{Al}(104.24 \mathrm{MHz})$ experimental $(\mathrm{a}-\mathrm{h})$ and calculated (i-p) (using parameters in Table 2) anisotropic traces for anorthite. The traces correspond to $\delta^{\prime}{ }_{\exp }$ of (a) 65.5, (b) 68.0, (c) 69.5, (d) 73.8, (e) 75.6 , (f) 84.7, (g) 88.0, and (h) $91.8 \mathrm{ppm}$, respectively. The calculated spectra were apodized by a Lorentzian line broadening of $10 \mathrm{~Hz}$.

$10 \mathrm{a}$ is the result of iterative fitting having a relative population (\%) of 14.1:12.9:11.7:15.6:10.0:13.3:12.7:9.8 for sites $1-8$, respectively. For comparison the experimental and simulated MAS spectra with the relative intensities and anisotropic parameters from the present analysis are displayed in Figure 11. The two spectra agree very well and the differences are believed to be caused by additional $\mathrm{Al}$ sites with less than $4 \mathrm{Si}$ second nearest neighbors.

On the basis of the relative site populations the short range order parameter was determined. In anorthite, $\mathrm{Si}$ and $\mathrm{Al}$ are both 4-coordinated and can be located in the same position in the crystal structure. According to Loewenstein's rule ${ }^{46}$ about aluminum avoidance $\mathrm{Al}-\mathrm{O}-\mathrm{Si}$ bonds are energetically favored over $\mathrm{Al}-\mathrm{O}-\mathrm{Al}$ bonds. This would be the situation in a perfectly ordered material. In the present case the number of $\mathrm{Al}-\mathrm{O}-\mathrm{Al}$ linkages $\left(N_{\mathrm{Al}-\mathrm{O}-\mathrm{Al}}\right)$ is derived from the intensity difference from the perfectly ordered value of 0.125 for each site. Thus, sites 1

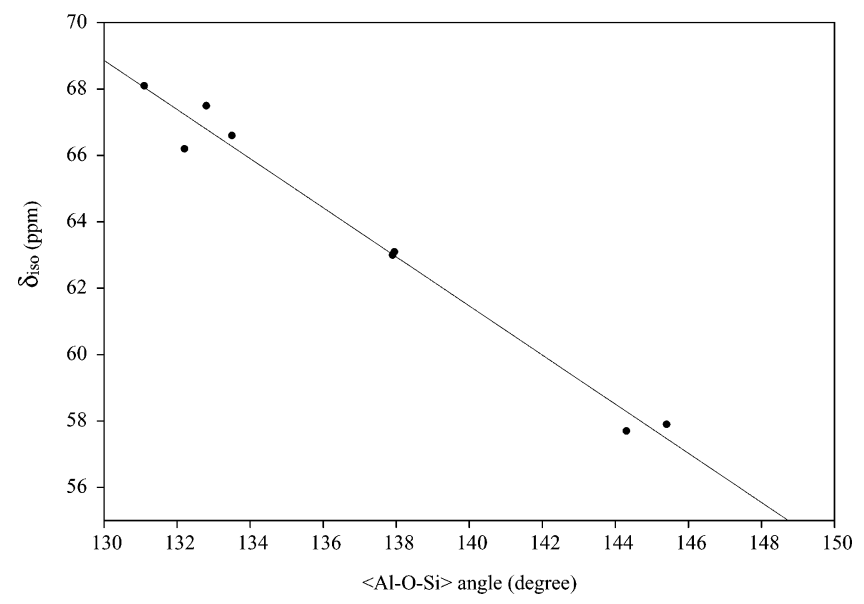

Figure 9. Plot of the ${ }^{27} \mathrm{Al}$ isotropic chemical shift $\left(\delta_{\text {iso }}\right)$ as a function of the average $\mathrm{Al}-\mathrm{O}-\mathrm{Si}$ bond angle $(\theta)$. The solid line is the best linear fit that corresponds to $\delta_{\text {iso }}=-0.74( \pm 0.04) \theta+165( \pm 6)$.

( $m z i 0), 2$ ( $m 0 i 0), 4(m 000), 6(00 i 0)$, and $7(0 z 00)$ contain the excess Al. The total excess intensity in these sites is 0.061 of total intensity. If we work out a short range order parameter, $\sigma$, from this then $\sigma=1-1 /{ }_{2} N_{\mathrm{Al}-\mathrm{O}-\mathrm{Al}}=0.970$, which is in agreement with the value of $0.968-0.989$ determined from ${ }^{29} \mathrm{Si}$ NMR for this sample by Phillips et al. ${ }^{5}$

Having determined the short range order parameter by the procedure described above for the well-ordered anorthite sample the disordered anorthites annealed at $1400{ }^{\circ} \mathrm{C}$ for between 1 min and $179 \mathrm{~h}$ have been analyzed by similar experiments. The isotropic projections of the MQ-QCPMG-MAS experiments are displayed in Figure 12. In accordance with previously published MQ-MAS spectra of synthetic anorthites in the glassy and crystalline state ${ }^{37}$ no $\mathrm{AlO}_{6}$ and $\mathrm{AlO}_{5}$ sites are observed. The spectra of the disordered samples (Figure 12a-f) exhibit considerably less well-resolved isotropic projections than the well-ordered sample. Besides the broader lines some general trends for the spectra of the disordered samples may be followed. The overall shape of the isotropic projections of the disordered samples covers a range from 62 to $100 \mathrm{ppm}$ for annealing time of $1 \mathrm{~min}$ whereas the range is $4 \mathrm{ppm}$ narrower, 64 to $98 \mathrm{ppm}$, for annealing time of $179 \mathrm{~h}$. In all spectra very intense resonances at the approximate positions of sites 4 and 7 in the crystalline sample are observed whereas the intensity around site 2 increases as a function of annealing time. It is noted that these three sites were among the ones with excess $\mathrm{Al}$ in the well-ordered sample. The intensity decreases in the region 78- 


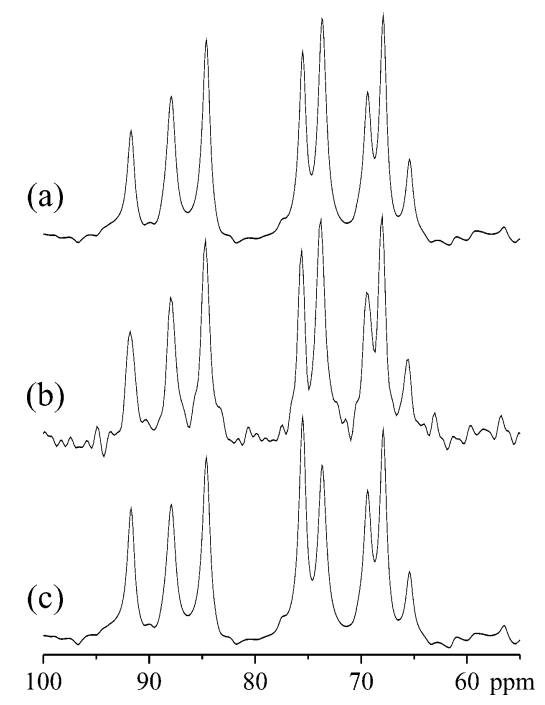

Figure 10. ${ }^{27} \mathrm{Al}(104.24 \mathrm{MHz})$ experimental (b) and calculated (a,c) (using parameters in Table 2) isotropic projections for anorthite. In the calculated spectrum (a) the isotropic spectrum is a linear combination of the individually calculated isotropic spectra with use of weightings of 0.141 (site 1), 0.129 (site 2), 0.117 (site 3), 0.156 (site 4), 0.100 (site 5), 0.133 (site 6), 0.127 (site 7), and 0.098 (site 8), respectively. The calculated spectrum (c) is an equally weighted sum of individually calculated isotropic spectra. In both calculated spectra Lorentzian line broadenings of 46.9 (site 1), 44.4 (site 2), 49.2 (site 3), 53.8 (site 4), 45.1 (site 5), 49.6 (site 6), 59.6 (site 7), and 47.1 (site 8) $\mathrm{Hz}$ were applied.

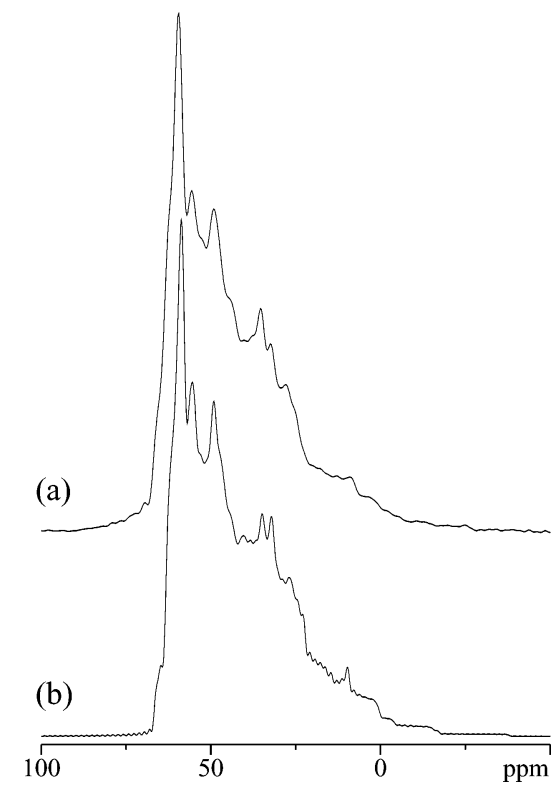

Figure 11. ${ }^{27} \mathrm{Al}(104.24 \mathrm{MHz})$ experimental (a) and calculated (b) (using parameters in Table 2) MAS spectra of anorthite. The experimental spectrum is a single pulse MAS spectrum acquired at a spin rate of $15000 \mathrm{~Hz}$, using a $0.5 \mu$ s excitation pulse (rf-field strength: 33 $\mathrm{kHz}$ ), a recycle delay of $6 \mathrm{~s}$, and 1024 scans. The calculated spectrum is calculated by using the experimental spin rate and ideal rf pulses. Lorentzian line broadenings of 1 and $40 \mathrm{~Hz}$ have been applied to the experimental and calculated spectra, respectively.

$83 \mathrm{ppm}$ as a function of annealing time and since no resonances are present in this region in the well-ordered sample this suggests that the resonances situated in this region originate from the presence of $\mathrm{Al}-\mathrm{O}-\mathrm{Al}$ linkages in the crystal. Moreover it is noted that the isotropic projection is primarily broadened toward higher isotropic shifts indicating larger values of either $\delta_{\mathrm{iso}}, C_{\mathrm{Q}}$, $\eta_{\mathrm{Q}}$ or a combination of these as $\mathrm{Al}-\mathrm{O}-\mathrm{Al}$ linkages are removed. In the isotropic projections of the annealed samples it

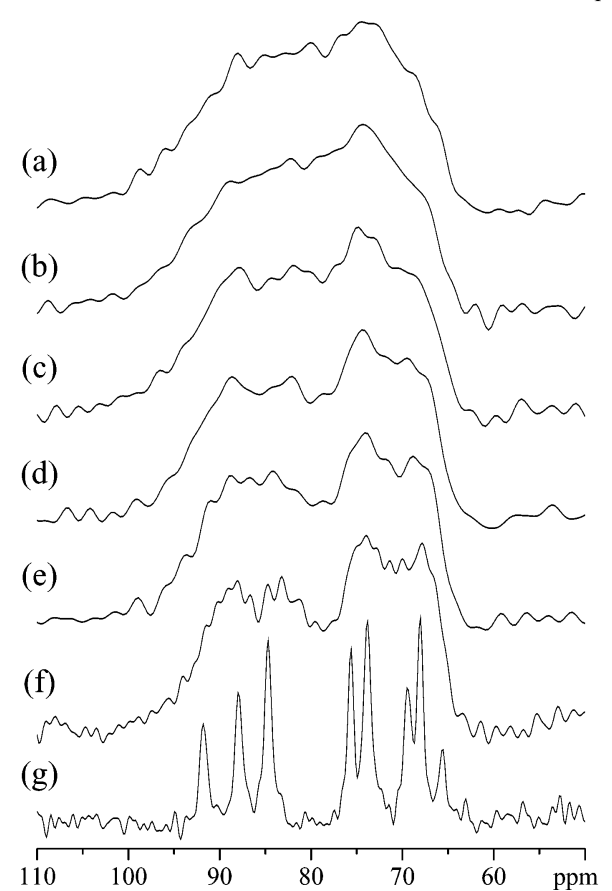

Figure 12. Isotropic projections from experimental ${ }^{27} \mathrm{Al}(104.24 \mathrm{MHz})$ MQ-QCPMG-MAS spectra of anorthite samples annealed at $1400{ }^{\circ} \mathrm{C}$ for (a) 1 , (b) 4, (c) 15, (d) 150, (e) 2820 (47 h), and (f) 10740 (179 h) min. The spectrum in part $g$ is the isotropic projections of crystalline anorthite. The experimental conditions for acquisition and processing of the MQ-QCPMG-MAS spectra of the annealed samples are the same as in Figure 7 except that 192 scans for each of the $40 t_{1}$ steps with a recycle of $2.0 \mathrm{~s}$ have been used.

TABLE 3: Lower Levels for the $N_{\mathrm{Al}-\mathrm{O}-\mathrm{Al}}$ and the Corresponding Maximum Short Range Order Parameter, $\sigma$

\begin{tabular}{cccc}
\hline & & & $\sigma$ from \\
annealing time & $\min .\left(N_{\mathrm{Al}-\mathrm{O}-\mathrm{Al}}\right)$ & $\sigma_{\max }$ & ${ }^{29} \mathrm{Si}$ MAS NMR \\
\hline $1 \mathrm{~min}$ & 0.284 & 0.858 & 0.802 \\
$4 \mathrm{~min}$ & 0.282 & 0.859 & 0.815 \\
$15 \mathrm{~min}$ & 0.268 & 0.868 & 0.865 \\
$2.5 \mathrm{~h}$ & 0.240 & 0.880 & 0.886 \\
$47 \mathrm{~h}$ & 0.233 & 0.884 & 0.901 \\
$179 \mathrm{~h}$ & 0.204 & 0.898 & 0.905
\end{tabular}

${ }^{a}$ Reference 5 .

is only possible to determine the upper limit for the order parameter. The regions $78-83$ and $93-105 \mathrm{ppm}$ that are not populated in the well-ordered sample must contain resonances due to $\mathrm{Al}-$ $\mathrm{O}-\mathrm{Al}$ linkages and therefore their relative abundance will be a lower limit for the number of $\mathrm{Al}-\mathrm{O}-\mathrm{Al}$ bonds. Table 3 displays the results of these integrals along with the corresponding maximum order parameter and the order parameters determined previously. The integrals are not corrected for the magnitude of $C_{\mathrm{Q}}$, but except for site 1 this does not introduce large errors and it is rather unlikely that site 1 would be shifted to the two regions with no intensity in the spectrum of the well-ordered anorthite. Compared to the results obtained from ${ }^{29} \mathrm{Si} \mathrm{MAS}$ $\mathrm{NMR}^{5}$ the upper limits agree well for the samples with annealing times from 1 to 15 min whereas the upper limit is below the previously determined values for longer annealing times.

To verify if the broad lines in the isotropic projections were caused by distributions in either EFG parameters or distributions in isotropic chemical shifts the MQ-QCPMG-MAS spectra were carefully examined. The MQ-QCPMG-MAS spectra of the anorthite samples annealed for $1 \mathrm{~min}$ (a) and $179 \mathrm{~h}$ (b), respectively, are displayed in Figure 13. In both spectra the lines for distribution of isotropic chemical shifts (positive slope) and EFG parameters (negative slope) are included as a guide to the 


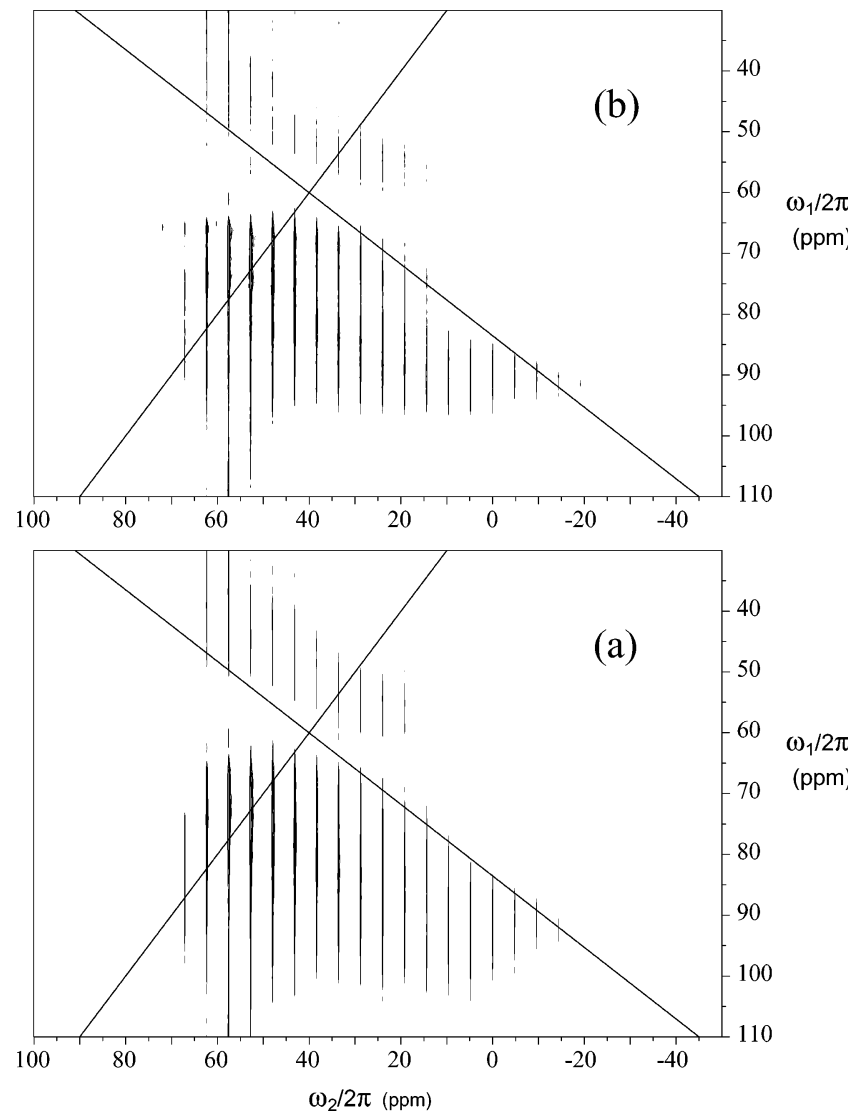

Figure 13. Experimental ${ }^{27} \mathrm{Al}(104.24 \mathrm{MHz})$ MQ-QCPMG-MAS spectra of anorthite samples annealed at $1400{ }^{\circ} \mathrm{C}$ for (a) 1 and (b) 10740 min $(179 \mathrm{~h})$, respectively.

eye. Besides the shift range 60-105 ppm where the isotropic resonances are positioned an additional ridge from the spinning sidebands is observed. Even though this ridge does not look like a line with a slope of $-10 / 17$ probably because of a mixture of sidebands originating from sites characterized by fixed EFG parameters and sites characterized by a distribution of these parameters the negative slope of the ridge indicates that at least one of the $\mathrm{Al}$ sites is characterized by a distribution of EFG parameters. From the position of the spinning sidebands around $\delta_{\exp }^{\prime}=40-45 \mathrm{ppm}$ the centerband is situated at $\delta_{\exp }^{\prime}=70.6-$ $75.6 \mathrm{ppm}$, which is in the region of sites 4 and 5. As expected the intensity of the ridge is higher in the sample annealed for 1 min than in the one annealed for $179 \mathrm{~h}$, which is in accordance with the higher degree of order as a function of annealing time. Summing up on the anorthites this indicates that site 4 ( $m 000)$, in particular, plays a major role in the ordering. First of all, this site contains the most $\mathrm{Al}$ in the well-ordered sample, and second it is characterized by high intensity and quite likely a distribution of EFG parameters in the annealed samples.

\section{Conclusions}

In this work it has been demonstrated that accurate relative site populations can be determined from MQ-QCPMG-MAS spectra by iterative fitting of the spectrum of kyanite. By this procedure the short range order parameter for a highly ordered anorthite was then obtained based upon the relative site populations. Similar experiments on disordered anorthites made it possible to determine upper limits for the order parameter. Compared to previous results from ${ }^{29} \mathrm{Si}$ MAS NMR the improved resolution in the ${ }^{27} \mathrm{Al}$ MQ-QCPMG-MAS spectra of the ordered anorthite provided significantly more site specific information about the anorthites.
Acknowledgment. This research was supported by grants from the United Kingdom Joint Infrastructure Fund (JIF) and Joint Research Equipment Initiative (JREI). Professor M. A. Carpenter, University of Cambridge, is gratefully acknowledged for providing the samples of kyanite and anorthite.

\section{References and Notes}

(1) Lippmaa, E. T.; Alla, M. A.; Pehk, T. J.; Engelhardt, G. J. Am. Chem. Soc. 1978, 100, 1929.

(2) Lippmaa, E.; Mägi, M.; Samoson, A.; Engelhardt, G.; Grimmer, A.-R. J. Am. Chem. Soc. 1980, 102, 4889.

(3) Putnis, A.; Angel, R. J. Phys. Chem. Miner. 1985, 12, 217.

(4) Ramdas, S.; Klinowski, J. Nature 1984, 308, 521.

(5) Phillips, B. L.; Kirkpatrick, R. J.; Carpenter, M. A. Am. Miner. 1992, 77, 484.

(6) Stebbins, J. F.; Murdoch, J. B.; Carmichael, I. S. E.; Pines, A. Phys. Chem. Miner. 1986, 13, 371.

(7) Engelhardt, G.; Michel, D. High-resolution solid-state NMR of silicates and zeolites; Wiley: New York, 1987.

(8) Llor, A.; Virlet, J. Chem. Phys. Lett. 1988, 152, 248.

(9) Chmelka, B. F.; Mueller, K. T.; Pines, A.; Stebbins, J.; Wu, Y.; Swanziger, J. W. Nature 1989, 339, 42.

(10) Mueller, K. T.; Sun, B. Q.; Chingas, G. C.; Zwanziger, J. W.; Terao, T.; Pines, A. J. Magn. Reson 1990, 86, 470.

(11) Samoson, A.; Lippmaa, E.; Pines, A. Mol. Phys. 1988, 65, 1013.

(12) Wu, Y.; Sun, B. Q.; Pines, A.; Samoson, A.; Lippmaa, E. J. Magn. Reson. 1990, 89, 297.

(13) Gan, Z. J. Am. Chem. Soc. 2000, 122, 3242.

(14) Gan, Z. J. Chem. Phys. 2001, 114, 10845.

(15) Frydman, L.; Harwood: J. S. J. Am. Chem. Soc. 1995, 117, 5367.

(16) Medek, A.; Harwood, J. S.; Frydman, L. J. Am. Chem. Soc. 1995, 117,12779 .

(17) Fernandez, C.; Amoureux, J. P. Chem. Phys. Lett. 1995, 242, 449.

(18) Wu, G.; Rovnyak, D.; Sun, B.; Griffin, R. G. Chem. Phys. Lett. 1995, 249, 210.

(19) Amoureux, J. P.; Pruski, M.; Lang, D. P.; Fernandez, C. J. Magn. Reson. 1998, 131, 170

(20) Larsen, F. H.; Nielsen, N. C. J. Phys. Chem. A 1999, 103, 10825.

(21) Wu, G.; Rovnyak, D.; Griffin, R. G. J. Am. Chem. Soc. 1996, 118 , 9326.

(22) Marinelli, L.; Medek, A.; Frydman, L. J. Magn. Reson. 1998, 132 88 .

(23) Ding, S.; McDowell, C. A. J. Magn. Reson. 1998, 135, 61.

(24) Kentgens, A. P. M.; Verhagen, R. Chem. Phys. Lett. 1999, 300, 435 .

(25) Madhu, P. K.; Goldbourt, A.; Frydman, L.; Vega, S. Chem. Phys. Lett. 1999, 307, 41.

(26) Madhu, P. K.; Goldbourt, A.; Frydman, L.; Vega, S. J. Chem. Phys. 2000, 112, 2377.

(27) Goldbourt, A.; Madhu, P. K.; Vega, S. Chem. Phys. Lett. 2000, 300,435 .

(28) Vosegaard, T.; Florian, P.; Massiot, D.; Grandinetti, P. J. J. Chem. Phys. 2001, 114, 4618.

(29) Vosegaard, T.; Larsen, F. H.; Jakobsen, H. J.; Ellis, P. D.; Nielsen, N. C. J. Am. Chem. Soc. 1997, 119, 9055

(30) Lefort, R.; Wiench, J. W.; Pruski, M.; Amoureux, J.-P. J. Chem. Phys. 2002, 116, 2493.

(31) Delaglio, F.; Grzesiek, S.; Vuister, G. W.; Zhu, G.; Pfeifer, J.; Bax, A. J. Biomol. NMR 1995, 6, 277.

(32) Amoureux, J.-P.; Fernandez, C. Solid State NMR 1998, 10, 211.

(33) Bodenhausen, G.; Kogler, H.; Ernst, R. R. J. Magn. Reson. 1984, 58,370 .

(34) Amoureux, J.-P.; Fernandez, C.; Frydman, L. Chem. Phys. Lett. 1996, 259,347

(35) Zaremba, S. K. Ann. Matematica Pura Appl. 1966, 73, 293.

(36) Carpenter, M. A. Am. Miner. 1991, 76, 1110.

(37) Baltisberger, J. H.; Xu, Z.; Stebbins, J. F.; Wang, S. H.; Pines, A. J. Am. Chem. Soc. 1996, 118, 7209 .

(38) Brown, S. P.; Wimperis, S. J. Magn. Reson. A 1997, 128, 42.

(39) Alemany, L. B.; Steuernagel, S.; Amoureux, J.-P.; Callender, R. L.; Barro, A. R. Solid State NMR 1999, 14, 1.

(40) Ashbrook, S. E.; Wimperis, S. J. Am. Chem. Soc. 2002, 124, 11602

(41) Smith, M. E.; Jaeger, C.; Schoenhofer, R.; Steuernagel, S. Chem. Phys. Lett. 1994, 219, 75

(42) Brinkmann, D.; Staehli, J. L. Helv. Phys. Acta 1968, 41, 274.

(43) Staehli, J. L.; Brinkmann, D. Z. Kristallogr. 1974, 140, 260.

(44) Wainwright, J. E.; Starkey, J. Z. Kristallogr. 1971, 133, 75.

(45) Phillips, B. L.; Kirkpatrick, R. J.; Putnis, A. Phys. Chem. Miner. 1989, 16, 591 .

(46) Loewenstein, W.; Loewenstein, M. Am. Miner. 1954, 39, 92. 